\title{
3D Printed and Photonically Cured Graphene UHF RFID Tags on Textile, Wood, and Cardboard Substrates
}

\author{
M. Akbari, ${ }^{1}$ H. He, ${ }^{1}$ J. Juuti, ${ }^{2}$ M. M. Tentzeris, ${ }^{3}$ J. Virkki, ${ }^{1}$ and L. Ukkonen ${ }^{1}$ \\ ${ }^{1}$ BioMediTech Institute and Faculty of Biomedical Sciences and Engineering, Tampere University of Technology, Tampere, Finland \\ ${ }^{2}$ Microelectronics Research Unit, University of Oulu, Oulu, Finland \\ ${ }^{3}$ School of Electrical and Computer Engineering, Georgia Institute of Technology, Atlanta, GA, USA
}

Correspondence should be addressed to M. Akbari; mitra.akbari@tut.fi

Received 3 April 2017; Accepted 22 May 2017; Published 20 June 2017

Academic Editor: Yizhu Shen

Copyright (C) 2017 M. Akbari et al. This is an open access article distributed under the Creative Commons Attribution License, which permits unrestricted use, distribution, and reproduction in any medium, provided the original work is properly cited.

\begin{abstract}
This paper introduces 3D direct writing and microdispensing of graphene ultrahigh frequency (UHF) radio-frequencyidentification (RFID) antennas on textile, wood, and cardboard substrates, subsequently cured either by conventional oven or photonically by pulsed Xenon flashes. Photonic-cured passive UHF RFID graphene tags on cardboard, wood, and textile substrates achieve read ranges of 5.4, 4.6, and 4 meters, respectively. These results are superior to those achieved by the oven-cured tags that featured read ranges of $4.8,4.5$, and 3.6 meters, respectively. This work presents the first integration of $3 \mathrm{D}$ printing and photonic curing of graphene antennas on low-cost versatile substrates.
\end{abstract}

\section{Introduction}

Recently, 3D direct writing and microdispensing have gained a great interest as they have the capability of printing versatile materials eliminating the need of masks and feature sizes as small as $20 \mu \mathrm{m}$, as well as offering significant reductions in the amount of used material. 3D direct writing opens great possibilities in printing, for example, electrically functional radio-frequency (RF) devices, antennas, and wearable electronics [1-3].

Integrating additive manufacturing processes with a photonic curing process enables the rapid and cost-effective manufacturing of electronics. The mechanism of photonic curing is based on rapid heating of films by intense photon flux and cooling via conduction, and it has been a transformative process in printed electronics manufacturing. The photonic curing allows for inexpensive, rapid, and completely maskless thermal processing along with excellent controllability. The use of pulsed light from a flash lamp is an excellent alternative to traditional thermal processing $[4,5]$.

Metallic antenna additive manufacturing components have been extensively utilized in antenna manufacturing $[5,6]$. However, these are relatively expensive, require high curing temperature, and involve many nonenvironmentallyfriendly aspects, such as nonbiodegradable and toxic chemicals and solvents. Therefore, the utilization of alternative, nonmetallic components, such as carbonous nanomaterials, has gained a lot of attention. In particular, graphene shows extraordinary properties, including high charge mobility $\left(200,000 \mathrm{~cm}^{2} \mathrm{~V}^{-1} \mathrm{~s}^{-1}\right)$, zero band gap, and high mechanical properties (with Young modulus of $\sim 1 \mathrm{TPa}$ ) [7, 8]. Additionally, utilizing graphene in antenna structures brings great possibilities, such as lightweight components, low curing temperatures, and especially low cost compared to metallic materials $[7,9]$.

Recent works $[9,10]$ have demonstrated graphene-based antennas for passive radio-frequency-identification (RFID) applications. In antenna manufacturing, doctor blading and screen-printing have been utilized. The main limitation of these two methods is their inherent nonflexibility in design changes, due to the need of a stencil.

In this work, we present ultrahigh frequency (UHF) RFID antennas fabricated by 3D printing environmental-friendly graphene inks on three different green substrates. The printed antennas were cured by heat in a conventional oven or by photonic curing with a flash lamp. Various tag antenna 


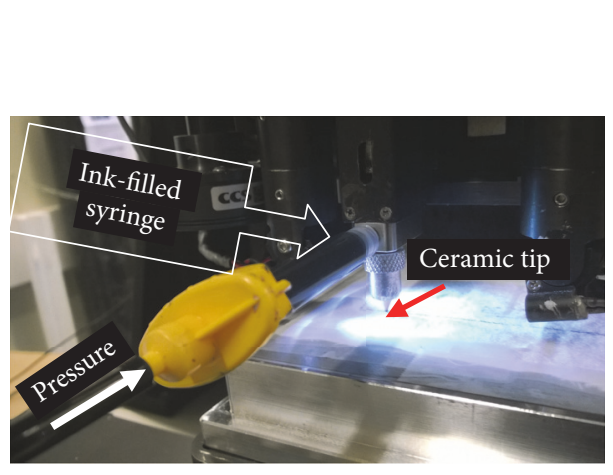

(a)

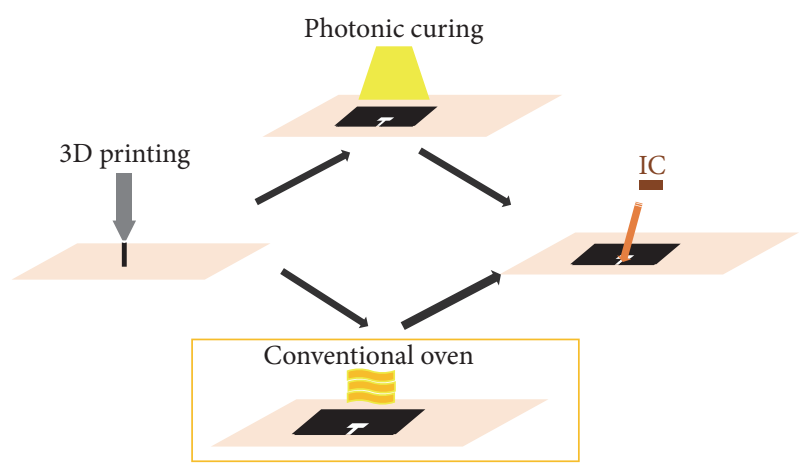

(b)

FIGURE 1: (a) 3D microdispensing system with an ink syringe and a ceramic nozzle tip and (b) schematic process of antenna fabrication.

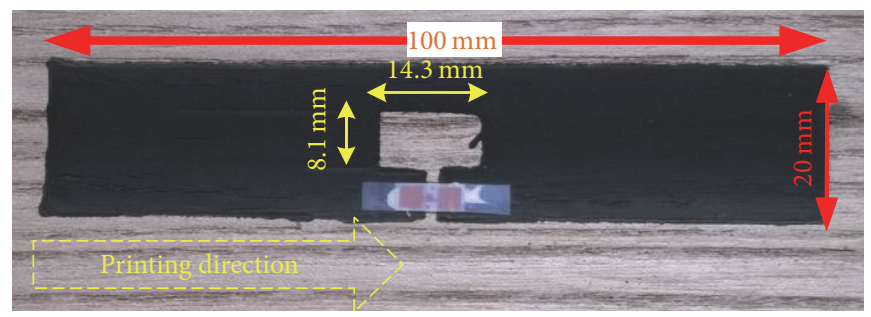

(a)

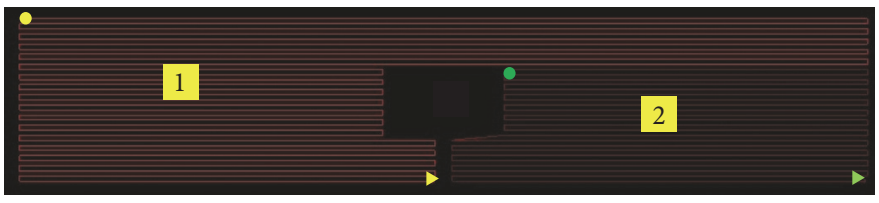

(b)

FIGURE 2: (a) 3D-printed RFID tag antenna (one layer) on wood and (b) image of printing direction.

prototypes are presented on textile, wood, and cardboard substrates, and the effects of the two curing methods on the tag performance are studied.

\section{Direct Write Microdispensing}

We used nScrypt tabletop series 3D direct write microdispensing system to fabricate the graphene-based UHF RFID tags on different substrates. The system was equipped with a positive pressure pump with a high-precision computer actuated valve coupled with a nozzle. The air pressure was applied to the ink-filled syringe (See Figure 1(a) for the 3D printing system), which was pushed into the main valve body, finally through the ceramic nozzle tip. By adjusting a constant material pressure and running a customizable computercontrolled valve "open and close" process, it can produce a controllable and consistent material flow rate, precise starts and stops, and the ability to utilize a wide range of material viscosities [11]. Furthermore, other critical parameters are the adjustment of the distance between the ceramic tip and the substrate, the speed of the tip, and the diameter of the nozzle tip. The latter was chosen according to the printed material and the final printing feature size.
In this work, the used ink was functionalized Graphene Nanoplatelets (GNPs) ink (HDPlas ${ }^{\circledR}$ IGSC02002; Haydale Ltd., UK [12]), which was used to fabricate antennas on a $100 \%$ cotton fabric (thickness of $0.3 \mathrm{~mm}$ ), normal rough packaging cardboard (thickness of $0.6 \mathrm{~mm}$ ), and thin wood veneer (thickness of $0.65 \mathrm{~mm}$ ). The printed antennas were then cured by a continuous pulsed light or in an oven, as shown in Figure 1.

In this study, the tag antenna was selected to be a simple dipole as shown in Figure 2(a). The used ceramic tip in the direct writing system had an inner diameter/outer diameter of $125 \mu \mathrm{m} / 175 \mu \mathrm{m}$, and the pressure for the material's feed was adjusted to 16 psi. The printing spacing and angle were 250 microns and $0^{\circ}$, respectively, and the printing direction was parallel to the wood veneer as shown in Figure 2(a). Figure 2(b) shows that printing was carried out in two parts, as well as the starting and ending points.

The printing resolution generally depends on the ceramic tip diameter, the substrate material, and the used ink. The wetting and absorption of the ink are affected by the substrate material properties. For instance, the width of a single printed graphene line (having a length of $10 \mathrm{~mm}$ ) on cardboard, textile, and wood was approximately 450,550 , and $650 \mu \mathrm{m}$, 
TABLE 1: Resistance of a printed graphene line on cardboard with different curing parameters.

\begin{tabular}{|c|c|c|c|c|c|c|c|c|c|c|}
\hline \multirow{2}{*}{ Curing method } & \multirow[t]{2}{*}{ Office conditions } & \multirow{2}{*}{$\begin{array}{l}\text { Oven } \\
60^{\circ} \mathrm{C}\end{array}$} & \multicolumn{8}{|c|}{ Photonic (HV, number of pulses, and duration of whole curing process) } \\
\hline & & & $1900 \mathrm{~V}$ & $1900 \mathrm{~V}$ & $2100 \mathrm{~V}$ & $2100 \mathrm{~V}$ & $2200 \mathrm{~V}$ & $2200 \mathrm{~V}$ & $2300 \mathrm{~V}$ & $2300 \mathrm{~V}$ \\
\hline \multirow{2}{*}{ Parameters } & \multirow[t]{2}{*}{$24 \mathrm{~h}$} & \multirow{2}{*}{$30 \mathrm{~min}$} & 8 & 16 & 8 & 24 & 8 & 16 & 8 & 16 \\
\hline & & & $15 \mathrm{~s}$ & $30 \mathrm{~s}$ & $15 \mathrm{~s}$ & $45 \mathrm{~s}$ & $15 \mathrm{~s}$ & $30 \mathrm{~s}$ & $15 \mathrm{~s}$ & $30 \mathrm{~s}$ \\
\hline$R(\Omega)$ & 60 & 29 & 40 & 32 & 40 & 27 & 35 & 32 & 35 & 45 \\
\hline
\end{tabular}

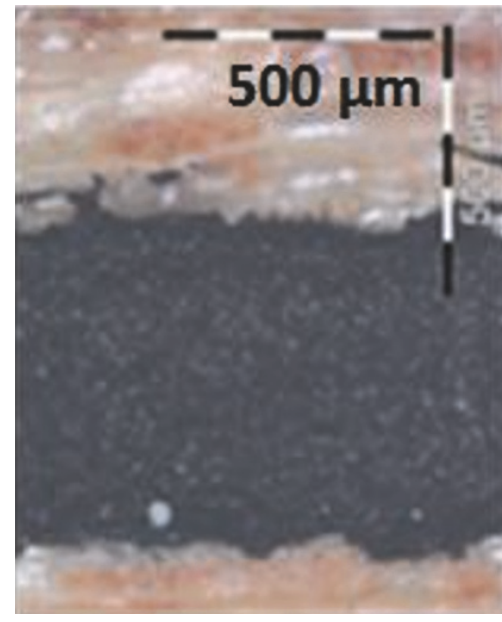

(a)

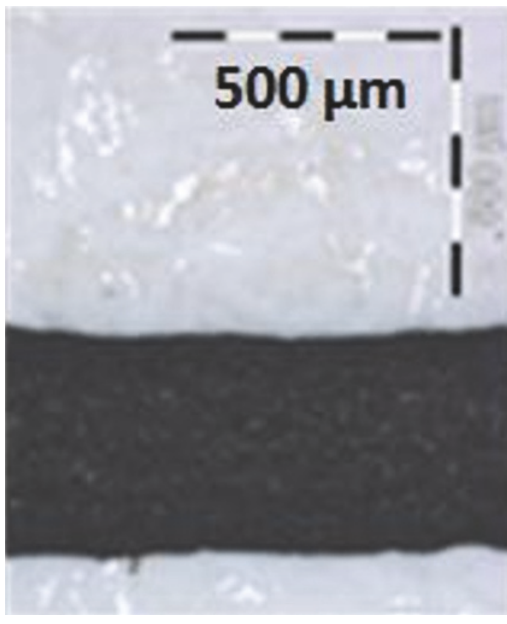

(b)

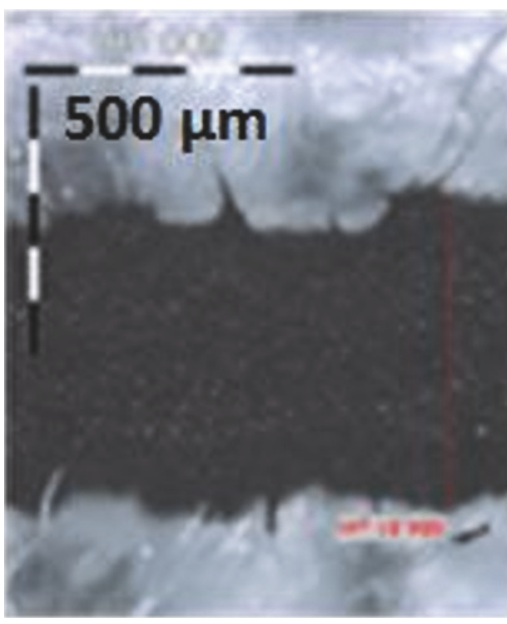

(c)

FIGURE 3: Optical microscopic image of a single, one-layer graphene line deposited by 3D microdispenser on (a) wood, (b) cardboard, and (c) textile (magnification $\times 5)$.

respectively. These printed lines are presented in Figure 3. As can be easily observed, the printed line on cardboard shows the best quality in terms of ink spreading and keeping fine boundaries compared to wood and fabric.

\section{Curing: Conventional Oven versus Photonic Curing}

The printed sample lines were subjected to a series of flashes from a Xenon sintering system (Sinteron 2010-L, Xenon Corp.), where the distance from the test sample to the window of the lamp housing was $25 \mathrm{~mm}$. The used operating mode was continuous mode, as a single pulse was not sufficient to cure the graphene layer, and eventually left it wet. In the continuous mode, three parameters are adjustable: high voltage $(\mathrm{HV})$ value, pulse width, and period. The principle of the continuous flash mode is presented in Figure 4. A static pulse width and period were used, and the HV value and the number of pulses were adjusted to find out the optimized parameters for the printed graphene layers. Initially, the optimized parameters for the printed $10 \mathrm{~mm}$ long lines were studied on the cardboard substrate. For comparison, samples were also cured in an oven at $60^{\circ} \mathrm{C}$ for 30 minutes, as presented in the ink datasheet [12], and in normal office conditions for 24 hours.

The printed lines on cardboard were subjected to a flash created with $\mathrm{HV}$ in the range of $1900 \mathrm{~V}$ to $2300 \mathrm{~V}$, and a different number of pulses were used with the pulse width
Duration of photonical curing process

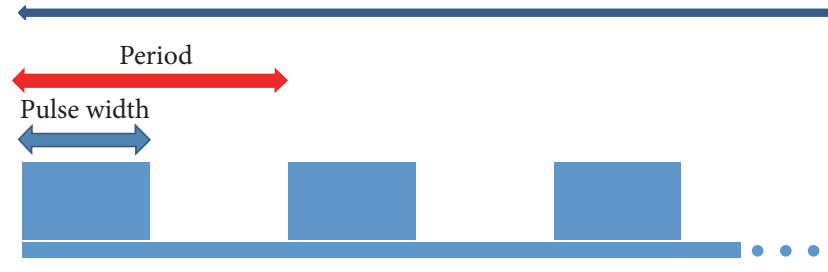

FIGURE 4: Continuous flash mode.

of $2100 \mu \mathrm{s}$ and a period of $1100 \mathrm{~ms}$. The resistances of the cured samples were measured by a multimeter and they are presented in Table 1. It was noticed that the cardboard starts burning when subjected to pulses with a HV more than $2300 \mathrm{~V}$. As can be seen from Table 1, there is a threshold, that is, $1900 \mathrm{~V}$ and $2100 \mathrm{~V}$ with 8 pulses, both producing a resistance of $40 \Omega$. The resistance started to decrease when the voltage was increased to $2200 \mathrm{~V}$ and more pulses were used. However, there is a risk of bumps creation and delamination by further increasing the number of pulses. In general, using a high HV and a large number (above 8) of pulses decreases the resistance value, unless it ends up to substrate burning or to the creation of undesired bumps.

By using continuous pulses (with a HV of $2200 \mathrm{~V}$ and overall eight pulses), the resistance of the sample line is about $35 \Omega$, which is close to the resistance of a sample cured in an oven. The highest resistance was achieved when the samples were left to cool off in office conditions. 


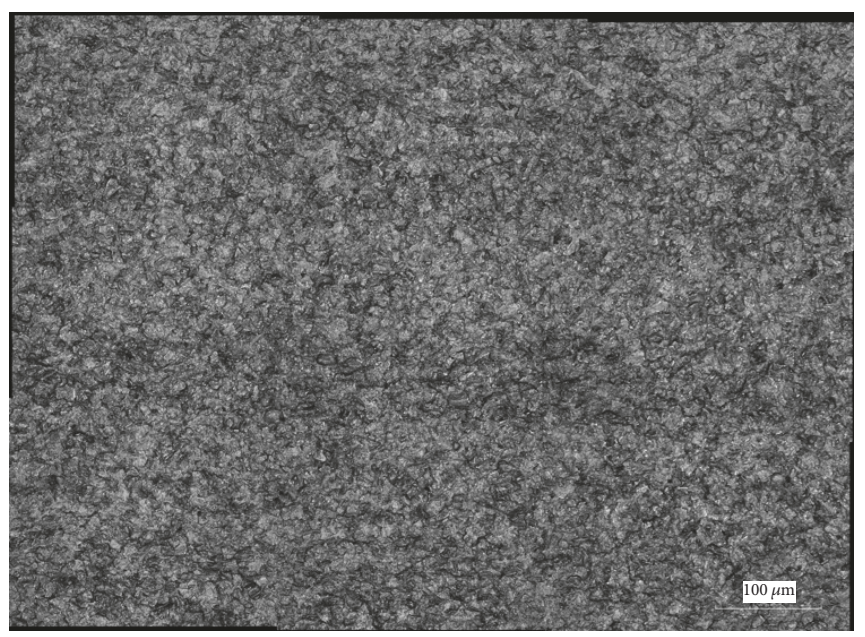

(a)

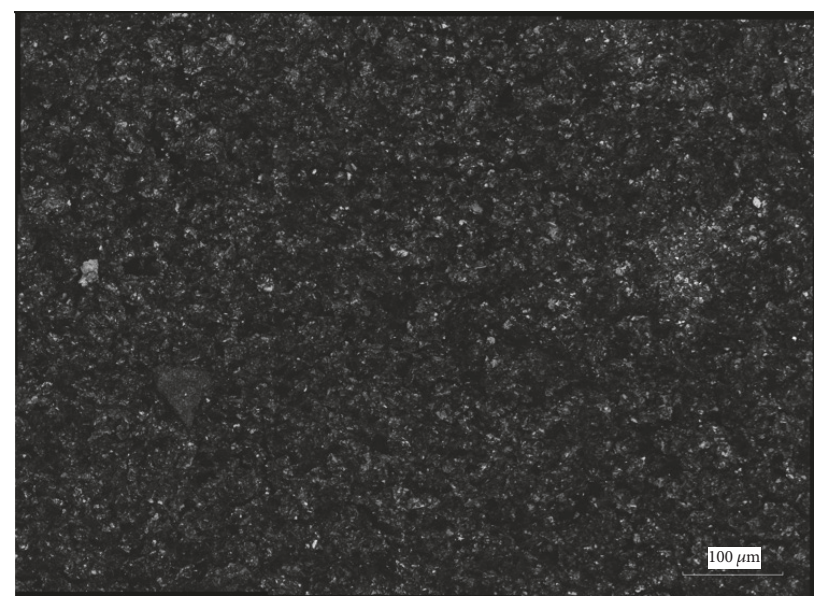

(c)

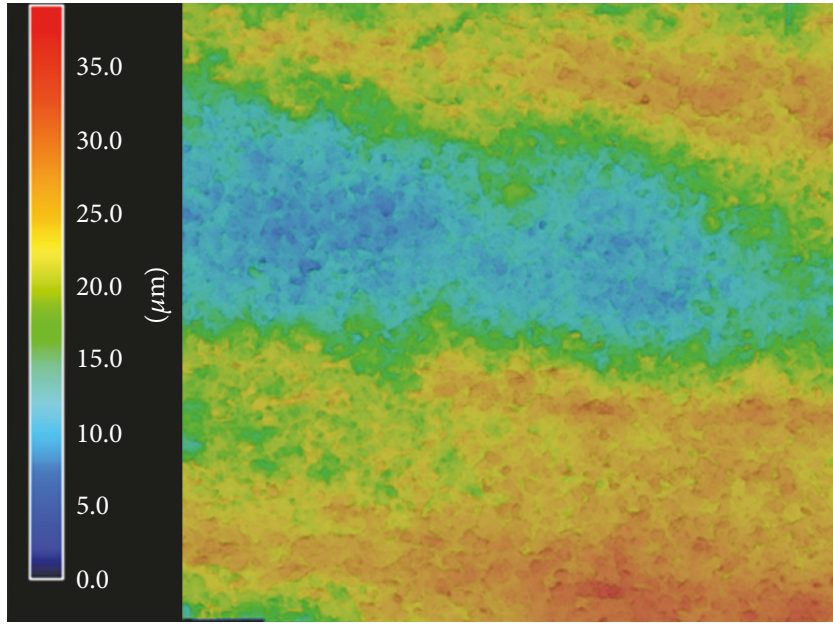

(b)

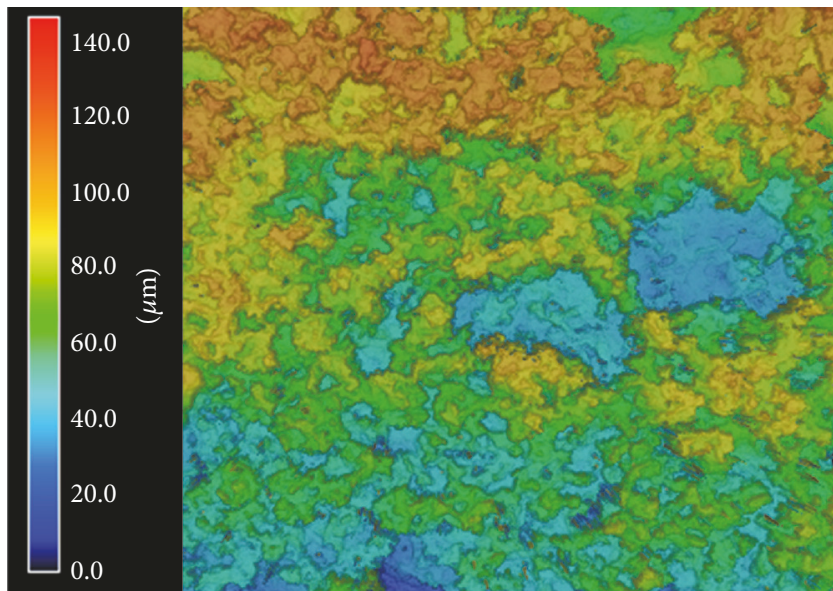

(d)

Figure 5: (a, b) Laser microscope and 3D topography images of oven-cured $\mathrm{C} 1$ and (c, d) photonic-cured C2.

In the case of the fabric and wood substrates, a lower HV, of about $1900 \mathrm{~V}$, is needed, due to the flammability of those substrates. The optimized pulsed Xenon flash parameters for curing graphene ink on different substrate materials are presented in Table 2.

\section{Materials Characterization}

The graphene UHF RFID tags printed on wood, cardboard, and fabric, and then cured in an oven, are referred to as samples $\mathrm{W} 1, \mathrm{Cl}$, and $\mathrm{F} 1$, respectively. The tags on wood, cardboard, and fabric, which were subjected to Xenon flash pulses, are referred to as samples $\mathrm{W} 2, \mathrm{C} 2$, and F2.

A 3D laser microscope (VK-X100/X200) was used to analyze the morphology and microstructure of the fabricated samples. According to the results presented in Figures 5-7 and Table 3, the difference between the microstructures and the 3D topography of the oven-cured and photoniccured samples is obvious. $\mathrm{Cl}, \mathrm{W} 1$, and $\mathrm{F} 1$ have a uniform microstructure and only a small difference between the highest and lowest thickness values. However, C2, W2, and
F2 show a larger thickness gradient and a less uniform microstructure.

Furthermore, the 4-point sheet resistances of the tags were measured by a manual probe station (Wentworth Labs) and a Keithley multimeter. Despite the fact that oven-cured samples are more uniform, the sheet resistances of the ovencured samples are higher than those of the photonic-cured samples. The reason is probably related to the fact that the printed layer is quite thick, so the nonuniformity of surface did not have dramatic effect on the sheet resistance. See Table 3 for these results.

Figure 8 shows the scanning electron microscope images of a cross-section of sample C2 (photonically cured antenna on cardboard), demonstrating that a $20 \mu \mathrm{m}$ thick layer of ink has penetrated. This shows excellent adhesion between the dispensed ink and substrate and leads to remarkable durability.

After the antenna manufacturing, the tag integrated circuits (IC) were attached. The utilized IC was NXP UCODE G2iL series RFID IC with a wake-up power of $-18 \mathrm{dBm}$ $(15.8 \mu \mathrm{W})$ that was provided by the manufacturer in a strap 


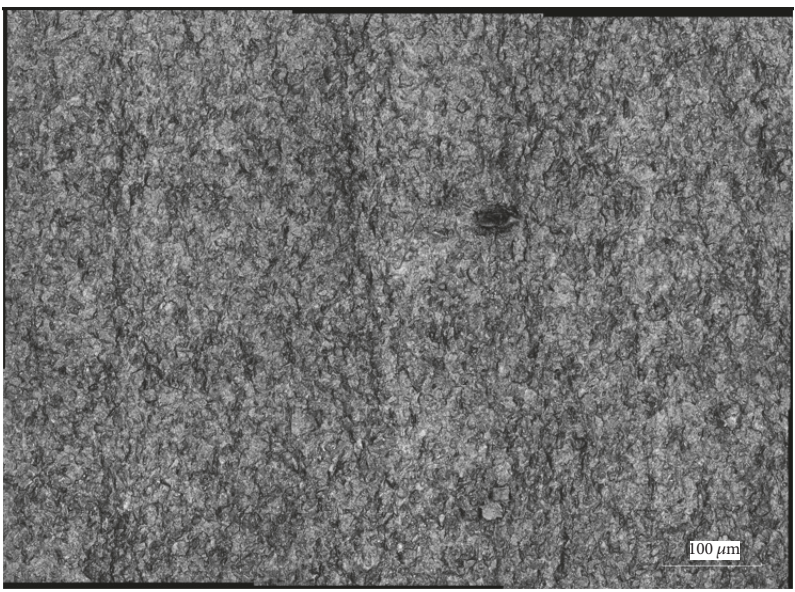

(a)

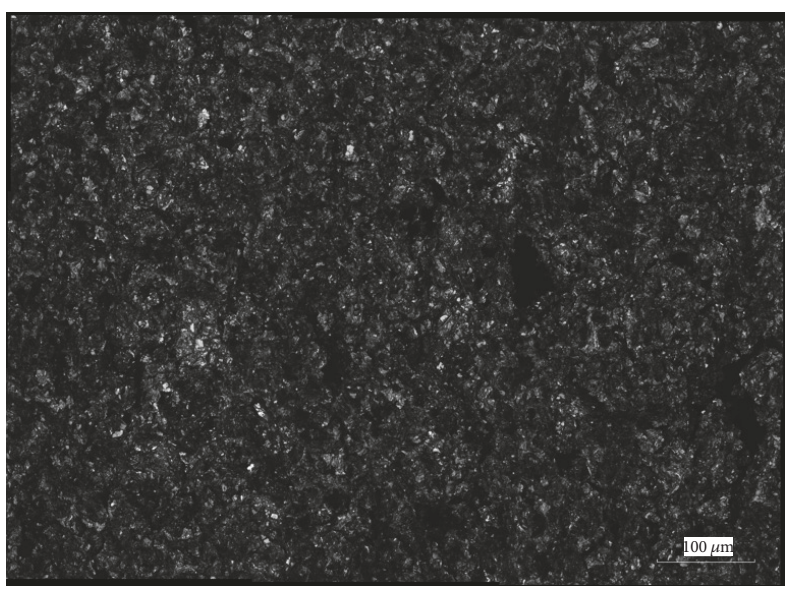

(c)
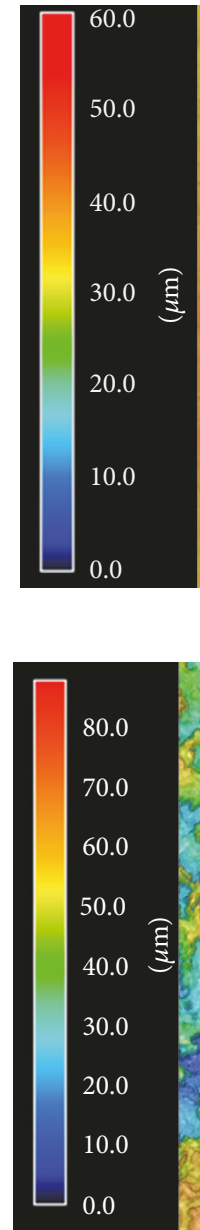

.0

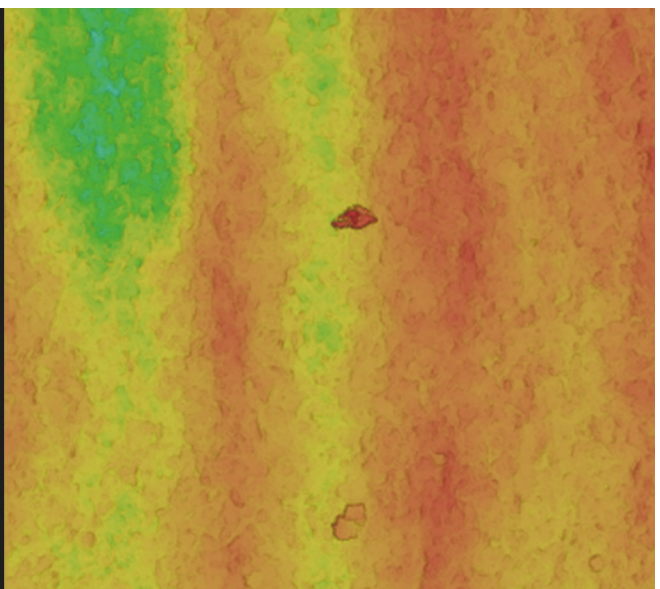

(b)

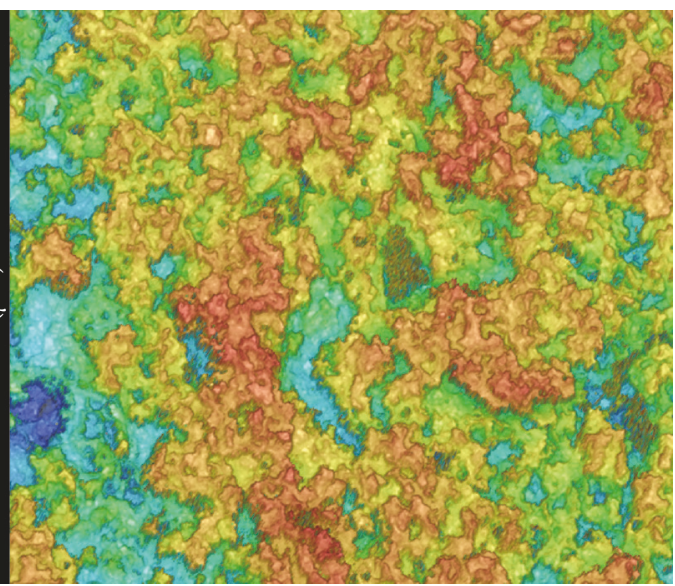

(d)

Figure 6: (a, b) Laser microscope and 3D topography images of oven-cured W1 and (c, d) photonic-cured W2.

TABLE 2: Optimized photonic curing parameters for different substrate materials.

\begin{tabular}{lccccc}
\hline Substrate & High voltage $(\mathrm{V})$ & $\begin{array}{c}\text { Pulse width } \\
(\mu \mathrm{s})\end{array}$ & Number of pulses & $\begin{array}{c}\text { Period } \\
(\mathrm{ms})\end{array}$ & $\begin{array}{c}\text { Duration of whole } \\
\text { curing process }(\mathrm{s})\end{array}$ \\
\hline Cardboard & 2200 & 2100 & 8 & 1100 & 15 \\
Wood & 1900 & 2100 & 6 & 1100 & 11 \\
Fabric & 1900 & 2100 & 6 & 1100 & 11 \\
\hline
\end{tabular}

TABLE 3: The peak read range of each tag antenna together with the corresponding thickness, average thickness gradient, and sheet resistance.

\begin{tabular}{|c|c|c|c|c|c|c|}
\hline & Substrate & Curing method & Read range $(\mathrm{m})$ & $\begin{array}{l}\text { Average thickness } \\
(\mu \mathrm{m})\end{array}$ & $\begin{array}{l}\text { Thickness gradient } \\
(\mu \mathrm{m})\end{array}$ & $\begin{array}{c}\text { 4-point sheet } \\
\text { resistance }(\Omega / s q)\end{array}$ \\
\hline $\mathrm{C} 1$ & \multirow{2}{*}{ Cardboard } & Oven & 4.8 & 17.6 & 35 & 31.84 \\
\hline $\mathrm{C} 2$ & & Photonic & 5.4 & 74 & 140 & 31.25 \\
\hline $\mathrm{F} 1$ & \multirow{2}{*}{ Fabric } & Oven & 3.6 & 91.2 & 90 & 27.40 \\
\hline $\mathrm{F} 2$ & & Photonic & 4 & 67 & 100 & 26.08 \\
\hline W1 & \multirow{2}{*}{ Wood } & Oven & 4.5 & 29.6 & 30 & 68.49 \\
\hline W2 & & Photonic & 4.6 & 51.3 & 80 & 48.50 \\
\hline
\end{tabular}




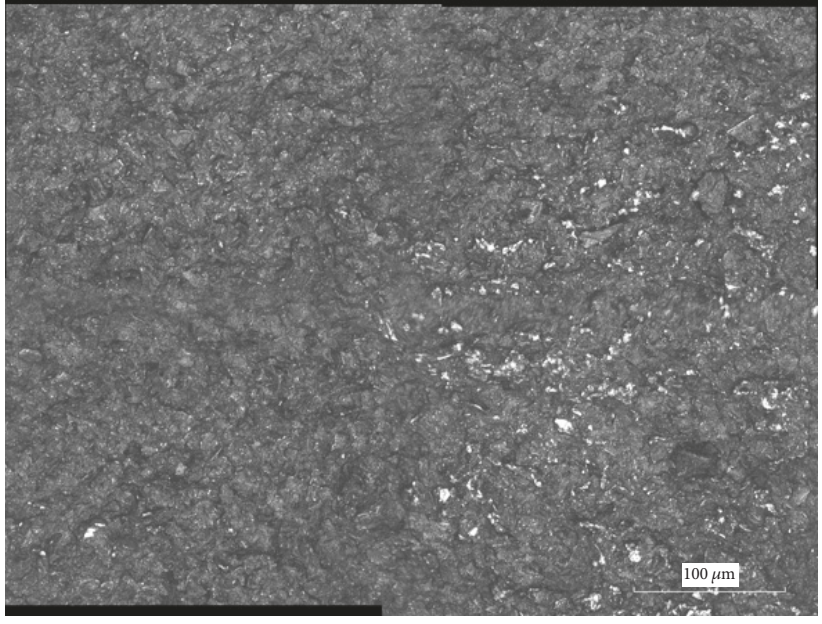

(a)

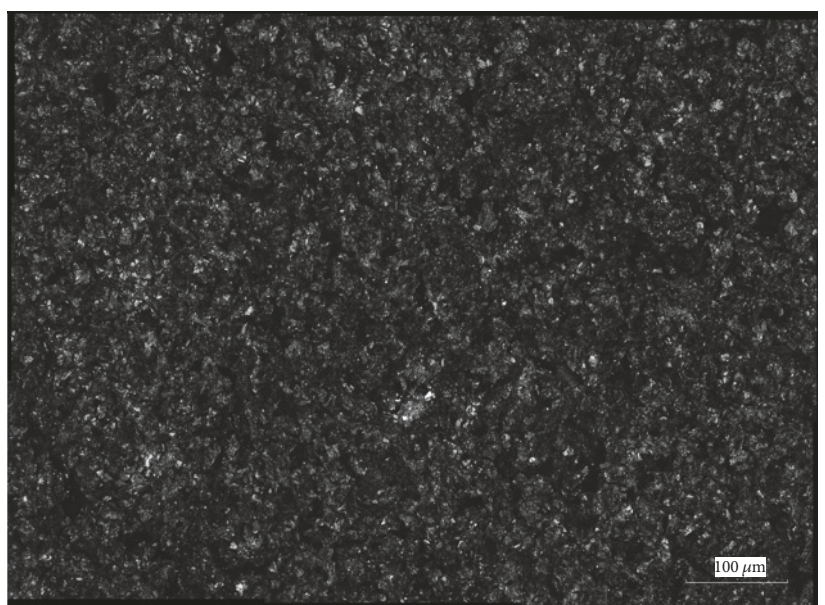

(c)

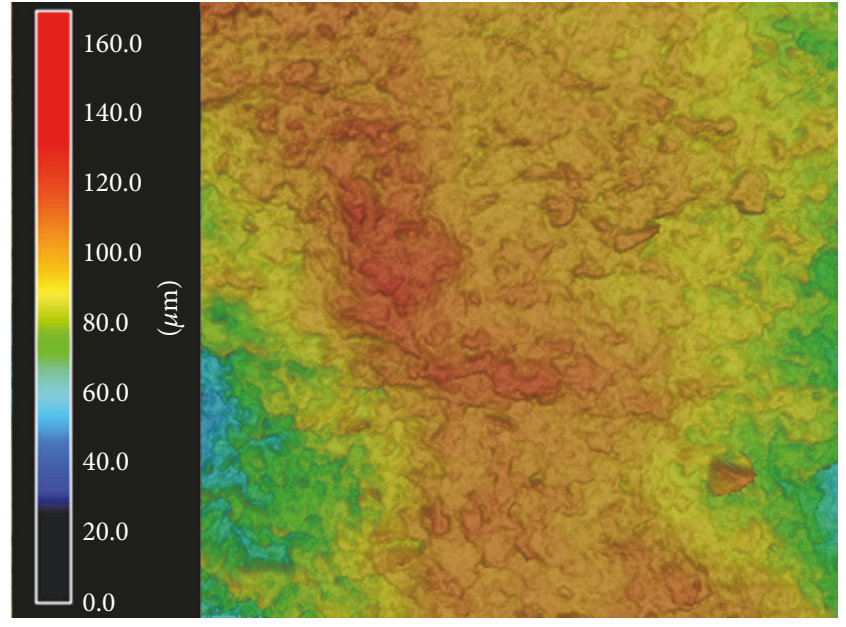

(b)

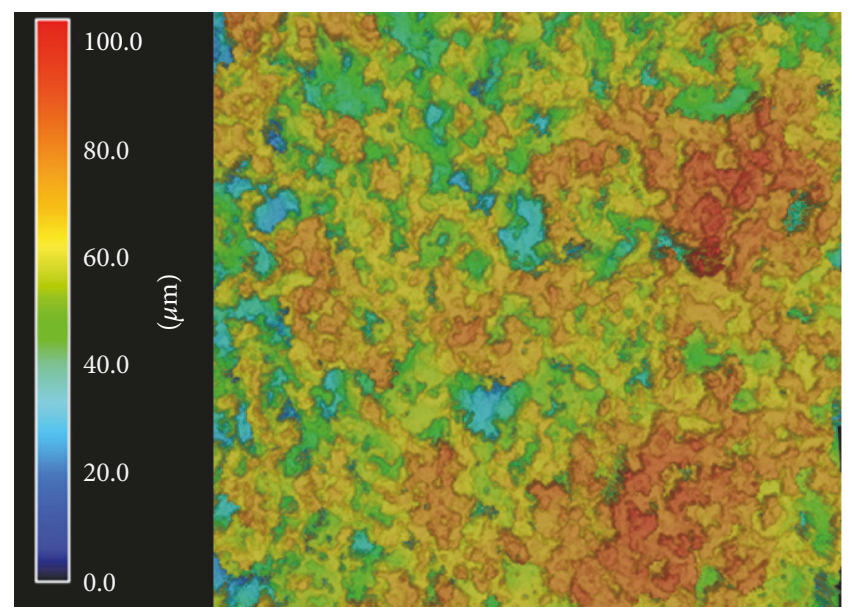

(d)

FIgURE 7: (a, b) Laser microscope and 3D topography images of oven-cured F1 and (c, d) photonic-cured F2.

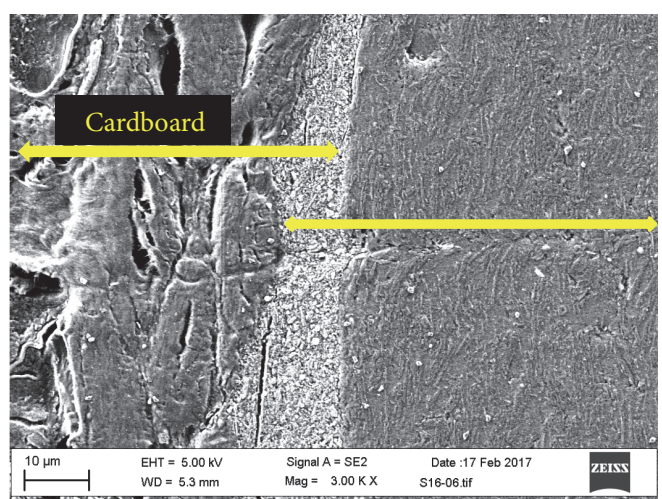

FIGURE 8: SEM image of a cross-section area of C2, which shows the graphene layer and cardboard interface.

structure with $3 \times 3 \mathrm{~mm}^{2}$ pads. The pads were attached to the antenna with conductive silver epoxy (Circuit Works CW2400).

\section{Wireless Measurements}

The tags' performances were wirelessly measured with a Voyantic Tagformance system [13]. It contains an RFID reader with an adjustable transmission frequency $(0.8 \cdots 1 \mathrm{GHz})$ and output power (up to $30 \mathrm{dBm}$ ) and providing the recording of the backscattered signal strength (down to $-80 \mathrm{dBm}$ ) from the tag under test.

The tag's lowest continuous-wave transmission power (threshold power: $P_{\mathrm{th}}$ ) was recorded. Here $P_{\mathrm{th}}$ is defined as the lowest power at which a valid 16-bit random number from the tag is received as a response to the query command in ISO 18000-6C communication standard. In addition, the wireless channel from the reader antenna to the location of the tag under test was first characterized using a system reference tag with known properties. As has been detailed in [14], this enabled us to estimate the attainable read range of the tag $\left(d_{\mathrm{tag}}\right)$ versus frequency from

$$
d_{\mathrm{tag}}=\frac{\lambda}{4 \pi} \sqrt{\frac{\operatorname{EIRP}}{\Lambda} \frac{P_{\mathrm{th}^{*}}}{P_{\mathrm{th}}}}
$$




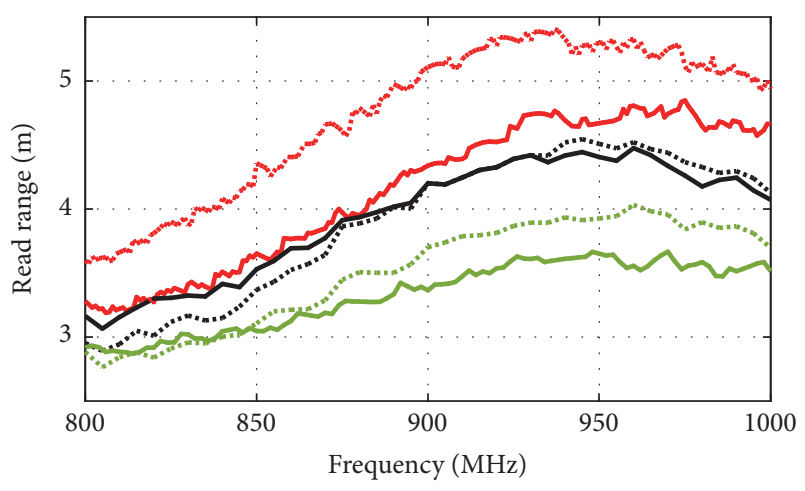

$\begin{array}{lrl}\text { C1: Oven-cured tag } & \ldots . . . & \text { W2: Photonic-cured tag } \\ \text { on cardboard } & & \text { on wood } \\ \ldots \ldots . & \text { C2: Photonic-cured tag } & \text { F1: Oven-cured tag } \\ \text { on cardboard } & & \text { on fabric } \\ \text { W1: Oven-cured tag } & \ldots . . . & \text { F2: Photonic-cured tag } \\ \text { on wood } & & \text { on fabric }\end{array}$

FIGURE 9: Read range values of oven- and photonic-cured graphene tags on cardboard (C1, C2), wood (W1, W2), and fabric (F1, F2).

where $\lambda$ is the wavelength transmitted from the reader antenna, $P_{\text {th }}$ is the measured threshold power of the tag, $\Lambda$ is a known constant describing the sensitivity of the system reference tag, $P_{\mathrm{th}^{*}}$ is the measured threshold power of the RFID system reference tag, and EIRP is the emission limit of an RFID reader, given as equivalent isotropic radiated power. Here EIRP $=3.28 \mathrm{~W}$, which is the emission limit in European countries.

Figure 9 shows the read range values of the 3D printed graphene RFID tags (from $800 \mathrm{MHz}$ to $1000 \mathrm{MHz}$ ) on cardboard, wood, and textile, fabricated by using the two different curing methods. According to the results shown in Figure 9 and Table 3, all photonic-cured tags feature longer read ranges compared to similar oven-cured samples. For instance, the read range peak for a photonic-cured tag on cardboard (C2) is about 5.4 meters, while it is about 4.8 meters for the ovencured tag $(\mathrm{C} 1)$. The tags on cardboard show longest read ranges, compared to tags on fabric and wood substrates. The reason lies on the properties of the substrate materials and depends on, for example, spreading of the ink on the substrate and absorption of the ink into the substrate, along with the photonic curing limitations of the antennas on fabric and wood, where a lower HV value and pulse numbers had to be used, compared to the cardboard samples (see Table 2 for the used curing/drying parameters).

The same tag antenna design has been previously fabricated from copper tape. This tag is a good reference for the fabricated graphene tags, and it showed peak read ranges of approximately 12 meters [15]. The same tag design has also been reported to be 3D-printed using silver and copper inks [16]. The achieved peak read ranges for the copper- and silverbased tags were around 6 and 11 meters, respectively. Thus, the graphene tags cannot yet offer comparable read ranges, due to the higher sheet resistance of the dispensed graphene layer.

The results achieved in this study show the effectiveness of photonic curing, which, based on these achieved outcomes, could replace the heating in case of printed graphene structures. This would significantly cut down the manufacturing time.

\section{Conclusion}

Using 3D printing and subsequent photonic curing introduces a fast and cost-effective way for graphene-based antenna manufacturing on versatile substrates. In this study, photonic-cured tags showed longer read ranges, from 4 to 5.4 meters, compared to similar oven-cured samples on all three studied substrates, textile, cardboard, and wood. To the best of our knowledge, these results are the first ones presenting $3 \mathrm{D}$ printed and photonically cured graphene antennas.

\section{Conflicts of Interest}

The authors declare no conflicts of interest regarding the publication of this paper.

\section{Acknowledgments}

This research is funded by Academy of Finland (Decisions nos. 285219 and 294534), Jane and Aatos Erkko Foundation, the Finnish Funding Agency for Technology and Innovation (TEKES), Tekniikan edistämissäätiö, and HPY Research Foundation.

\section{References}

[1] M. Vaezi, H. Seitz, and S. Yang, "A review on 3D micro-additive manufacturing technologies," International Journal of Advanced Manufacturing Technology, vol. 67, no. 5-8, pp. 1721-1754, 2013.

[2] P. Deffenbaugh, K. Church, J. Goldfarb, and X. Chen, "A. Manufacturing, and D. Printing, "Fully 3D Printed 2.4 GHz Bluetooth /Wi-Fi Antenna"," pp. 914-920, International Symposium on Microelectronics, 2013.

[3] I. T. Nassar and T. M. Weller, "An electrically-small, 3-D cube antenna fabricated with additive manufacturing," in Proceedings of the 2013 IEEE Topical Conference on Wireless Sensors and Sensor Networks, WiSNet 2013 - 2013 7th IEEE Radio and Wireless Week, RWW 2013, pp. 58-60, usa, January 2013.

[4] K. A. Schroder and P. D. Suite, "Mechanisms of Photonic Curing $^{\mathrm{TM}}$ : Processing High Temperature Films on Low Temperature Substrates," pp. 220-223, Nanotechnology: Electronics, Devices, Fabrication, MEMS, Fluidics and Computational, 2011.

[5] E. Sipilä, J. Liu, J. Wang et al., "Additive manufacturing of antennas from copper oxide nanoparticle ink: Toward low-cost RFID tags on paper- and textile-based platforms," in Proceedings of the 10th European Conference on Antennas and Propagation, EuCAP 2016, che, April 2016.

[6] M. L. Allen, K. Jaakkola, K. Nummila, and H. Seppa, "Applicability of metallic nanoparticle inks in RFID applications," IEEE Transactions on Components and Packaging Technologies, vol. 32, no. 2, pp. 325-332, 2009.

[7] T. Palacios, A. Hsu, and H. Wang, "Applications of graphene devices in RF communications," IEEE Communications Magazine, vol. 48, no. 6, pp. 122-128, 2010.

[8] H. Shen, L. Zhang, M. Liu, and Z. Zhang, "Biomedical applications of graphene," Theranostics, vol. 2, no. 3, pp. 283-294, 2012. 
[9] M. Akbari, J. Virkki, L. Sydanheimo, and L. Ukkonen, "The possibilities of graphene-based passive RFID tags in high humidity conditions," in Proceedings of the 2016 IEEE Antennas and Propagation Society International Symposium, APSURSI 2016, pp. 1269-1270, July 2016.

[10] X. Huang, T. Leng, X. Zhang et al., "Binder-free highly conductive graphene laminate for low cost printed radio frequency applications," Applied Physics Letters, vol. 106, no. 20, Article ID 203105, 2015.

[11] "Smart Pump," 2016. http://www.nscrypt.com/wp-content/ uploads/2017/02/2016-SmartPump-Gen2.pdf.

[12] “Technical Data Sheet - HDPlas ${ }^{\circledR}$ IGSC02002," 2015.

[13] Voyantic Ltd, "Voyantic Tagformance RFID Measurement Unit." http://voyantic.com/. 2015.

[14] J. Virkki, T. Björninen, S. Merilampi, L. Sydänheimo, and L. Ukkonen, "The effects of recurrent stretching on the performance of electro-textile and screen-printed ultra-highfrequency radio-frequency identification tags," Textile Research Journal, vol. 85, no. 3, pp. 294-301, 2015.

[15] G. Ginestet, N. Brechet, J. Torres et al., "Embroidered AntennaMicrochip Interconnections and Contour Antennas in Passive UHF RFID Textile Tags," IEEE Antennas and Wireless Propagation Letters, vol. 16, pp. 1205-1208, 2017.

[16] T. Björninen, J. Virkki, L. Sydanheimo, and L. Ukkonen, "Possibilities of 3D direct write dispensing for textile UHF RFID tag manufacturing," in Proceedings of the IEEE International Symposium on Antennas and Propagation \& USNC/URSI National Radio Science Meeting, pp. 1316-1317, IEEE, Vancouver, Canada, June 2015. 


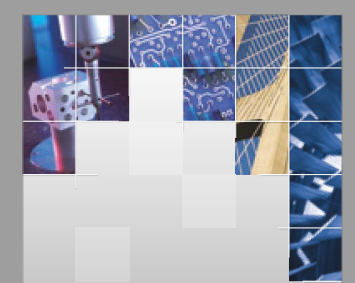

\section{Enfincering}
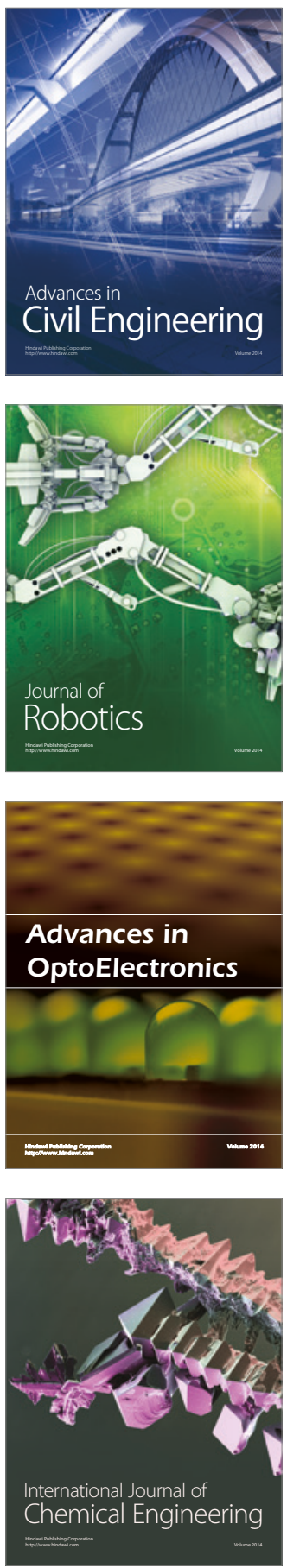

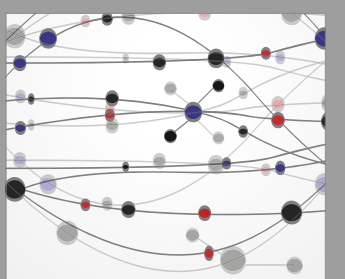

The Scientific World Journal

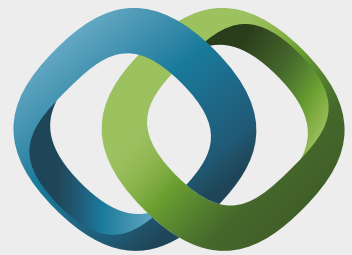

\section{Hindawi}

Submit your manuscripts at

https://www.hindawi.com
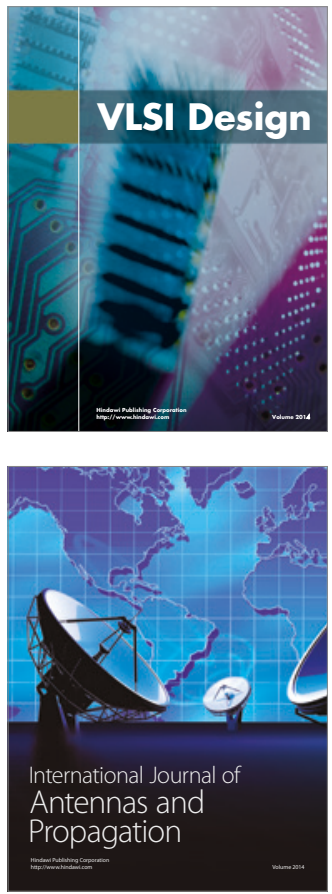

\section{Rotating}

Machinery
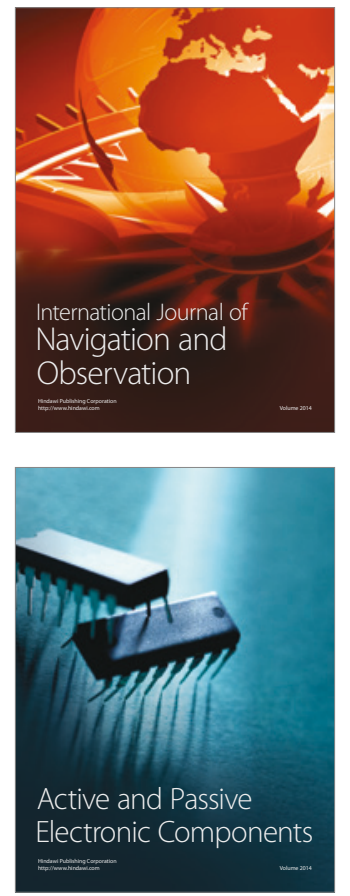
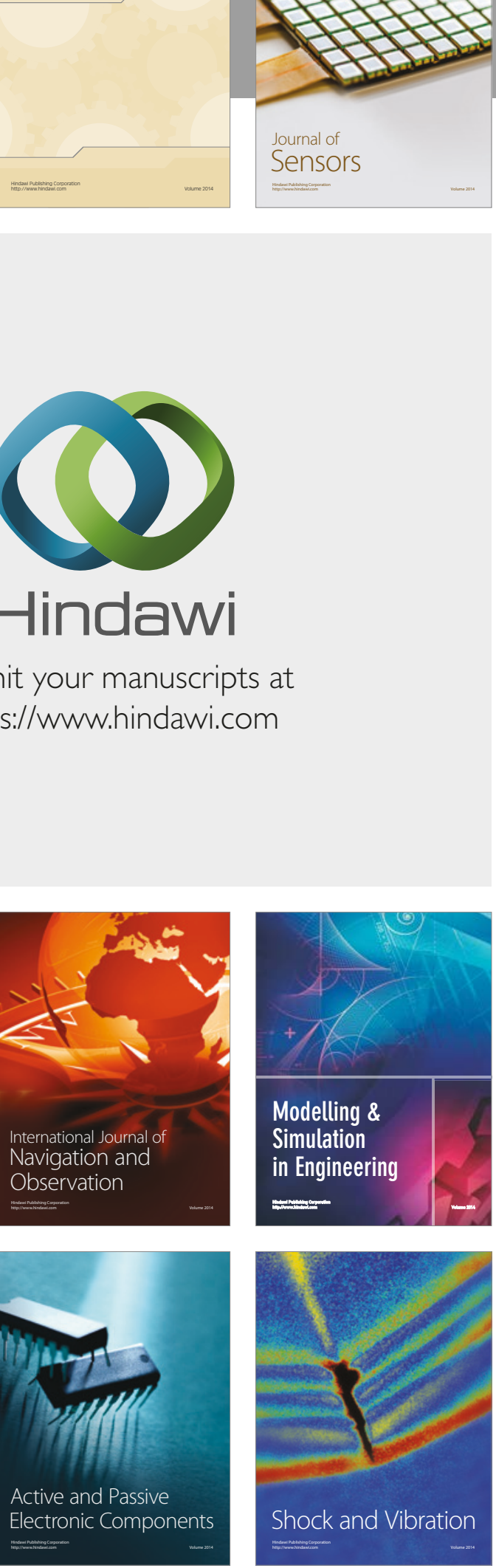
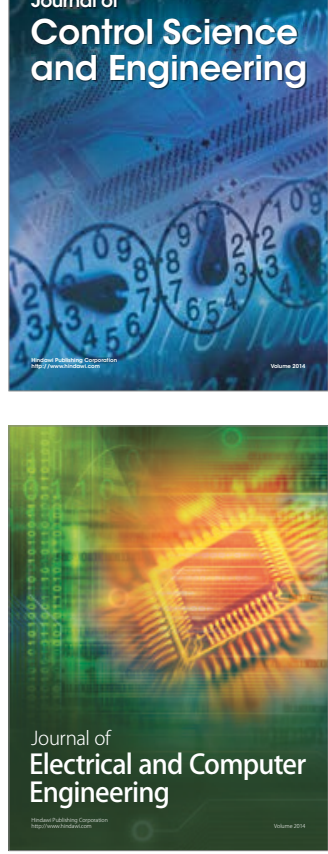

Distributed

Journal of

Control Science

and Engineering
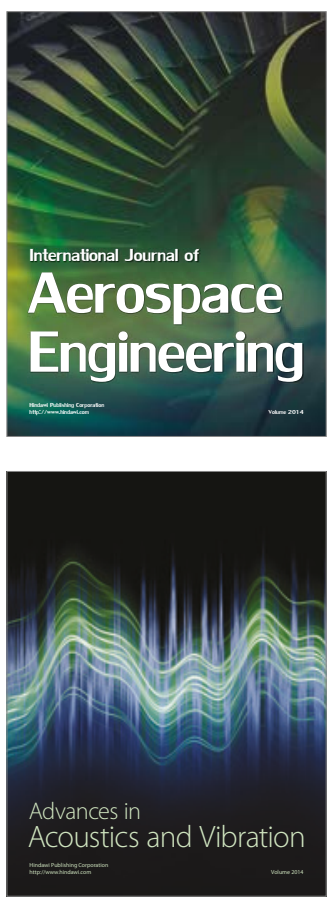

Sensor Networks 